\title{
АНАЛИЗ РАСПРОСТРАНЕННОСТИ И СТРУКТУРЫ БЕССИМПТОМНОГО НОСИТЕЛЬСТВА SARS-COV2 У ПОДРОСТКОВ И ВЗРОСЛЫХ В ПЕРИОД ЭПИДЕМИЧЕСКОГО ПОДЪЕМА ЗАБОЛЕВАЕМОСТИ COVID-19 В ЯНВАРЕ 2022 Г.
}

Башкетова Н.С. ${ }^{1}$, Фридман Р.К. ${ }^{2}$, Катаева И.С. ${ }^{1}$, Шапарь А.О. ${ }^{2}$, Костина M.А. ${ }^{3}$, Журавлев А.С. ${ }^{4}$, Пшеничная Н.Ю. ${ }^{5}$

1 Управление Федеральной службы по надзору в сфере защиты прав потребителей и благополучия человека по городу Санкт-Петербургу, 191025, Санкт-Петербург, Россия;

2 ФБУЗ «Центр гигиены и эпидемиологии в городе Санкт-Петербург» Роспотребнадзора, 192102, Санкт-Петербург, Россия;

${ }^{3}$ Федеральная служба по надзору в сфере защиты прав потребителей и благополучия человека 127994, Москва, Россия;

${ }^{4}$ ГБУЗ МО «Московский областной научно-исследовательский клинический институт им.

М.Ф.Владимирского», 129110, Москва Россия;

${ }^{5}$ ФБУН «Центральный научно-исследовательский институт эпидемиологии» Роспотребнадзора, 111124, Москва, Россия;

Корреспондирующий автор: Пшеничная Наталья Юрьевна. E-mail: pshenichnaya@cmd.su, ORCID 0000-0003-2570-711X, тел.: +7(918) 5535306.

\section{РЕЗЮМЕ}

Цель: провести анализ распространенности и структуры бессимптомного носительства SARS-CoV2 у студентов и преподавателей колледжей г.Санкт-Петербурга в период подъема заболеваемости COVID-19 в январе 2022.

Материалы и методы. В период с 25.01.2022 по 27.01.2022 проведен выборочный отбор проб из носоглотки и ротоглотки у 3886 из 8350 студентов и преподавателей 4-х колледжей, расположенных в разных районах г. Санкт-Петербурга. Обследуемый контингент не имел признаков ОРВИ и других симптомов, не исключающих COVID-19. Пробы исследовались методом ПЦР на PHK SARS-CoV2. Положительные пробы тестировали на мутации к вариантам «Омикрон» и «Дельта» с использованием лабораторной ПЦР-методики, разработанной ФБУН «НИИ эпидемиологии и микробиологии имени Пастера» Роспотребнадзора. Лабораторные исследования проводились на базе ФБУЗ «Центр гигиены и эпидемиологии в городе Санкт-Петербурге». 
Результаты. Продемонстрирована высокая частота выявления бессимптомных позитивных по SARS-CoV2 лиц среди студентов и преподавателей образовательных учреждений г. Санкт-Петербурга в период подъема заболеваемости COVID-19, вызванного преобладающим вариантом «Омикрон». В среднем, у подростков в возрасте 14-17 лет частота как положительных проб (20,6\%), так и удельный вес варианта «Омикрон» в позитивных пробах (51,7\%) были значимо выше, чем у лиц в возрасте 18 лет и старше ( 10,1\% и 33,1\%, соответственно). Указанная закономерность прослеживалась во всех анализируемых образовательных учреждениях. Подростки в возрасте 14-17 лет статистически значимо, в 2,3 раза чаще, являлись бессимптомными носителями вируса, чем взрослые. Кроме того, подростки 14-17 лет значимо чаще (в 3,3 раза) были инфицированы вариантом “Омикрон”, по сравнению с когортой исследуемых лиц в возрасте 18 лет и старше. Отмечена значимая прямая корреляционная связь между увеличением числа тестируемых и вероятностью выявления бессимптомных носителей, в том числе, инфицированных вариантом «Омикрон».

Выводы: в период подъема заболеваемости COVID-19 в январе 2022 года отмечается высокая распространенность бессимптомного носительства вируса SARS-CoV2 среди студентов и преподавателей образовательных учреждений, расположенных в разных районах города. Подростки более чем в 2 раза чаще являются носителями SARS-CoV2 и более чем в 3 раза чаще носителями варианта «Омикрон», по сравнению со взрослыми. Это демонстрирует нецелесообразность обследования и изоляции контактных лиц, из числа учащихся и преподавателей образовательных учреждений, не имеющих клинических проявлений инфекции. Сохраняет актуальность обследование и изоляция лиц с симптомами заболевания, перевод лиц из групп риска на дистанционный режим работы или обучения. а также усиленный контроль за соблюдением мер неспецифической профилактики во всех общественных учреждениях.

Ключевые слова: SARS-CoV-2, заболеваемость, «Омикрон», бессимптомное носительство, распространенность. 
ANALYSIS OF THE PREVALENCE AND STRUCTURE OF

ASYMPTOMATIC SARS-COV2 CARRIERS AMONG ADOLECENTS AND ADULTS IN SAINT-PETERSBURG DURING THE RISE OF EPIDEMIC CURVE IN JANUARY 2022

Bashketova N.S. ${ }^{1}$, Fridman R.K. ${ }^{2}$, Kataeva I.S. ${ }^{1}$, Shpari A.O. ${ }^{2}$, Kostina M.A. ${ }^{3}$, Zhuravlev A.S. ${ }^{4}$, Pshenichnaya N.Yu. ${ }^{5}$

${ }^{1}$ Department of the Federal Service for Supervision of Consumer Rights Protection and Human Welfare in the city of St. Petersburg, 191025, Saint-Petersburg, Russia;

${ }^{2}$ Federal Medical Institution "Center of Hygiene and Epidemiology in the city of Saint-Petersburg " of Rospotrebnadzor, 192102, Saint-Petersburg, Russia;

${ }^{3}$ Federal Service for Supervision of Consumer Rights Protection and Human Welfare 127994, Moscow, Russia;

${ }^{4}$ I.M. Sechenov First Moscow State Medical University of the Ministry of Health of the Russian Federation of the Ministry of Health of the Russian Federation (Sechenov University), 119048, Moscow Russia

${ }^{5}$ Central Research Institute of Epidemiology of Rospotrebnadzor, 111124, Moscow, Russia;

Corresponding author: Natalia Y. Pshenichnaya. E-mail: pshenichnaya@cmd.su OR-CID 0000-00032570-711 X, tel.: +7(918) 55306 .

\section{SUMMARY}

Aim: to analyze the prevalence and structure of asymptomatic SARS-CoV2 carriers among students and teachers of colleges in St. Petersburg during the rise in the incidence of COVID-19 in January 2022.

Materials and methods. In the period from 25.01.2022 to 27.01.2022, a selective sampling of samples from the nasopharynx and oropharynx was carried out in 3,886 out of 8,350 students and teachers of 4 colleges located in different districts of St. Petersburg. The examined contingent had no signs of acute respiratory infections and other symptoms that do not exclude COVID-19. The samples were examined by Real-time RT-PCR assay for detection SARS-CoV2 RNA using a test system produced by the Pasteur Institute of Epidemiology and Microbiology (Saint-Peterburg). Positive samples were tested for mutations to the Omicron and Delta variants using a laboratory PCR 
technique developed by the Central Research Institute of Epidemiology of Rospotrebnadzor. Laboratory studies were carried out on the basis of the Federal Budgetary healthcare institution "Center of Hygiene and Epidemiology in St. Petersburg".

Results. The high frequency of detection of asymptomatic SARS-CoV2-positive individuals among students and teachers of educational institutions of St. Petersburg during the period of the rise in the incidence of COVID-19 caused by the predominant variant "Omicron" was demonstrated. On average, in adolescents aged 14-17 years, the frequency of both positive samples (20.6\%) and the proportion of the Omicron variant in positive samples (51.7\%) were significantly higher than in persons aged 18 years and older (10.1\% and 33.1\%, respectively). This pattern was observed in all analyzed educational institutions. Adolescents aged 14-17 years were statistically significantly, 2.3 times more often, asymptomatic carriers of virusas than adults. In addition, adolescents aged 14-17 years were significantly more likely (3.3 times) to be infected with the Omicron variant, compared with the cohort of the studied individuals aged 18 years and older. A significant direct correlation was noted between an increase in the number of test subjects and the probability of detecting asymptomatic carriers, including those infected with the Omicron variant.

Conclusion: during the rise of epidemic curve of COVID-19 in January 2022, there is a high prevalence of asymptomatic SARS-CoV2 virus among students and teachers of educational institutions located in different districts of the city. Adolescents are more than 2 times more likely to be carriers of SARS-CoV2 and more than 3 times more likely to be carriers of the Omicron variant, compared with adults. This demonstrates the inexpediency of examining and isolating contact persons from among students and teachers of educational institutions who do not have clinical manifestations of infection. The examination and isolation of persons with symptoms of the disease, the transfer of persons from risk groups to a remote mode of work or training remains relevant. as well as enhanced monitoring of compliance with measures of non-specific prevention in all public institutions.

Keywords: SARS-CoV-2, morbidity, "Omicron", asymptomatic carrier, prevalence. 


\section{Введение}

Появление варианта B.1.1.529 (Омикрон) SARS-CoV-2, впервые выявленного в Ботсване и Южной Африке в ноябре 2021 года, ознаменовало начало новой волны пандемии [1]. «Омикрон» начал стремительно распространяться по планете и спустя немногом более месяца после его обнаружения, 27 декабря 2021, о его выявлении сообщили уже 110 государств. В январе 2022 года взрывной рост случаев заболевания произошел во многих странах мира, несмотря на продолжающиеся ограничения, обязательное соблюдение масочного режима, высокий процент серопозитивных лиц, перенесших в прошлом инфекцию или прошедших вакцинацию, что позволяло судить как о прорыве иммунной защиты, так и о более высокой трансмиссивности нового варианта вируса [2,3].

Используя моделирование на основе искусственного интеллекта было установлено, что вариант «Омикрон» в 10 раз заразнее исходного варианта SARS-CoV-2 и в 2 раза варианта Дельта. Считается, что это увеличение трансмиссивности связано с мутациями N440K, T478 K и N501Y [4] и, вследствие этого, большим тропизмом к клеткам эпителия верхних дыхательных путей и значительно меньшим - к альвеоцитам [5]. Закономерно, что преимущественная локализация в верхних дыхательных путях и высокая скорость передачи способствует и большому числу инфицированных индивидуумов [6].

O значении бессимптомных носителей SARS-CoV2 в трансмиссии вируса начали дискутировать еще во время первой волны пандемии. Считается, что одним из резервуаром вирусов у таких людей являются слюнные железы [7], отличающиеся высокой экспрессией ACE2 рецепторов. По мнению ряда авторов частота бессимптомного носительства может достигать 17-20\% [8,9]. Исследования, оценивающие долю бессимптомного носительства, ограничены неоднородностью определений случаев, неполной оценкой симптомов и неадекватным ретроспективным и перспективным наблюдением за лицами без клинических проявлений болезни [10], так как на практике примерно у 49\% людей, первоначально признанных бессимптомными, в дальнейшем развиваются симптомы болезни [11, 12]. Роль бессимптомных позитивных по SARS-CoV2 детей в распространении инфекции до настоящего времени является спорной, так как существующие мета-анализы не подтверждают их существенное эпидемиологическое значение в передаче SARS-CoV2. При этом акцентируется внимание на регистрируемую у детей-носителей вируса низкую вирусную 
нагрузку, что, возможно, препятствует передаче вируса $[13,14]$. С приходом варианта «Омикрон» стали появляться сообщения из ЮАР, Вьетнама, США, Японии о более высокой частоте выявления SARS-CoV2 у лиц без клинических проявлений инфекции $[15,16,17,18]$,

Особенности распространения «Омикрона» указывают на настоятельную необходимость лучшего понимания динамики передачи этого варианта вируса, включая бессимптомное распространение среди различных групп населения.

Цель работы: провести анализ распространенности и структуры бессимптомного носительства SARS-CoV2 у студентов и преподавателей выборочных образовательных учреждений г.Санкт-Петербурга в период подъема заболеваемости COVID-19 в январе 2022.

Материалы и методы. В период с 25.01.2022 по 27.01.2022 проведен выборочный отбор проб из носоглотки и ротоглотки у 3886 из 8350 студентов и преподавателей 4-х колледжей, расположенных в разных районах г. Санкт-Петербурга. Обследуемый контингент не имел признаков ОРВИ и других симптомов, не исключающих COVID-19. Пробы исследовались методом ПЦР на PHK SARS-CoV2 Положительные пробы методом ПЦР тестировали на мутации к вариантам «Омикрон» и «Дельта». Использовали тест-системы и лабораторную ПЦР методику на мутации к SARS-CoV2 ФБУН «НИИ эпидемиологии и микробиологии имени Пастера» Роспотребнадзора. Лабораторные исследования проводились на базе ФБУЗ «Центр гигиены и эпидемиологии в городе Санкт-Петербурге».

При статистической обработке результатов использовали программу SPSS Statistics 26.0. Для проверки нормальности распределения использовался метод Колмогорова-Смирнова с поправкой Лиллиефорса. В связи с распределением, отличным от нормального, количественный показатель представлялся в виде медианы (Me) с интерквартильным размахом (25-75\%Q). Межгрупповые различия оценивались при помощи U-критерия МаннаУитни. Сравнительный анализ независимых категориальных переменных проводился с применением $x^{2}$ Пирсона, либо точного теста Фишера. При проведении корреляционного анализа рассчитывался коэффициент корреляции Спирмена. Номинальный показатель представлялся абсолютным числом наблюдений, приведена процентная доля признака в подгруппах. Во всех процедурах статистического анализа критический уровень значимости принимали $\mathrm{p}<0,05$.

\section{Результаты}

Общая эпидемиологическая обстановка по COVID-19 в районах г. Санкт-Петербурга, где расположены анализируемые учебные заведения, в которых проводилось исследование, в 
даты забора проб характеризовалась высоким уровнем заболеваемости COVID-19 - от 92,8 до 240,7 на 100 тыс. населения (Табл.1).

Таблица 1

Динамика заболеваемости COVID-19 по районам, в которых проведено выборочное тестирование студентов Санкт-Петербурга с 25.01 по 27.01.2022

\begin{tabular}{|c|c|c|c|c|}
\hline \multirow{2}{*}{$\begin{array}{l}\text { Даты/ } \\
\text { заболеваемост } \\
\text { ь } \\
\text { на } 100 \text { тыс.нас. }\end{array}$} & \multicolumn{3}{|c|}{ Районы г. Санкт-Петербург } \\
\hline 25.01 & 201,2 & Кировский & Фрунзенский & Московский \\
\hline 26.01 & 176,4 & 188,8 & 205,6 & 163,2 \\
\hline $\begin{array}{c}\text { в сравнении с } \\
25.01 \text { в \% }\end{array}$ & $-12,3$ & $+\mathbf{1 0 3 , 4}$ & $-11,7$ & $\mathbf{+ 4 7 , 5}$ \\
\hline 27.01 & 235,2 & 179,3 & 247,8 & 237,6 \\
\hline $\begin{array}{c}\text { в сравнении с } \\
25.01 \text { в \% }\end{array}$ & $+\mathbf{3 3 , 3}$ & $-5,0$ & $+\mathbf{2 0 , 5}$ & $-1,3$ \\
\hline
\end{tabular}

Средний удельный вес выявленного варианта «Омикрон» в Санкт-Петербурге по результатам выборочного исследования материала в период с 25 по 27.01.2022 от лиц с лабораторно подтвержденным COVID-19 составил 73\% (из 2015 обследованных) у больных с манифестными формами болезни.

Всего в 4-х образовательных учреждениях обследовано на SARS-CoV2 3886 лиц, что составляет 46,5\% от списочного состава студентов и преподавателей. У $13,9 \%$ от всех обследованных (540 человек) получены положительные результаты ПЦР теста на SARS-CoV2. Из них в 320 пробах определили вариант SARS-CoV-2 «Омикрон» (59,3\%). Частота бессимптомного носительства варьировала в учебных заведениях от 12,8 до 17,2\%, а удельный вес варианта «Омикрон» в положительных пробах - от 42,1\% до 67,5\% (Табл.2).

У всех обследованных медианный возраст составил 18 лет (Q1-Q3: 17-19), у бессимптомных носителей - 17 лет (Q1-Q3: 16-18). При сравнении данных показателей с помощью U-критерия Манна-Уитни были установлены статистически значимые различия $(\mathrm{p}<0,001)$. 
При последующем анализе данных в динамике за период 25-27 января (Табл.2-3), были установлены статистически значимые прямые корреляционные связи между количеством проведенных тестов и выявлением бессимптомных случаев инфицирования штаммом “Омикрон” ( $\rho=1,000, p=0,01)$, а также между количеством положительных тестов и выявлением бессимптомных случаев инфицирования вариантом “Омикрон” ( $\rho=1,000, \mathrm{p}=0,01)$. Все выявленные связи имели весьма высокую тесноту по шкале Чеддока.

Установить статистически значимую корреляцию между уровнем заболеваемости COVID-19 в районах Санкт-Петербурга и частотой выявления бессимптомных случаев инфицирования SARS-CoV2 в образовательных учреждениях в соответствующих районах города не удалось.

\section{Таблица 2}

Удельный вес обследованных методом ПЦР на PHK SARS-CoV2 и выявленных положительных проб из числа студентов и преподавателей в образовательных учреждениях г. Санкт-Петербург

\begin{tabular}{|c|c|c|c|c|}
\hline $\begin{array}{c}\text { Наименование } \\
\text { учебного } \\
\text { заведения }\end{array}$ & $\begin{array}{c}\text { Всего } \\
\text { (ученики+препо } \\
\text { даватели) }\end{array}$ & $\begin{array}{c}\text { Из них } \\
\text { обследовано, } \\
\text { \%/n }\end{array}$ & $\begin{array}{c}\text { Всего } \\
\text { положительных } \\
\text { проб, \%/n }\end{array}$ & $\begin{array}{c}\text { Из них штамм } \\
\text { «Омикрон», } \\
\% / n\end{array}$ \\
\hline $\begin{array}{c}\text { СПб ГБПОУ } \\
\text { "Академия } \\
\text { машиностроени } \\
\text { я им. } \\
\text { Ж.Я.Котина" } \\
\end{array}$ & 1360 & $\begin{array}{c}66,62+6,2 / \\
906\end{array}$ & $\begin{array}{c}17,22 / \\
156\end{array}$ & $\begin{array}{c}64,10 / \\
100\end{array}$ \\
\hline $\begin{array}{c}\text { Петровский } \\
\text { колледж }\end{array}$ & 3522 & $\begin{array}{c}32,51 / \\
1145\end{array}$ & $\begin{array}{c}10,57 / \\
121\end{array}$ & $\begin{array}{c}42,15 / \\
51\end{array}$ \\
\hline $\begin{array}{c}\text { СПб ГБПОУ } \\
\text { "Академия } \\
\text { транспортных } \\
\text { технологий" }\end{array}$ & 2520 & $\begin{array}{c}48,69 / \\
1227\end{array}$ & $\begin{array}{c}15,08 / \\
185\end{array}$ & $\begin{array}{c}67,57 / \\
125\end{array}$ \\
\hline $\begin{array}{c}\text { Техникум } \\
\text { Отраслевых } \\
\text { Технологий }\end{array}$ & 948 & $64,14 / 608$ & $\begin{array}{c}12,83 / \\
78\end{array}$ & $\begin{array}{c}56,41 / \\
44\end{array}$ \\
\hline $\begin{array}{c}\text { ИТОГО по всем } \\
\text { учреждениям }\end{array}$ & 8350 & $\begin{array}{c}46,54 / \\
3886\end{array}$ & $13,90 / 540$ & $\begin{array}{c}59,26 / \\
320\end{array}$ \\
\hline
\end{tabular}

При более детальном анализе, было установлено, что количество выполненных тестов и количество положительных тестов в период с 25 по 27 января значимо коррелировало с 
частотой выявления варианта «Омикрон» в СПб ГБПОУ "Академия машиностроения им. Ж.Я.Котина" ( $\rho=1,000, p=0,01$ и ), а также в техникуме Отраслевых Технологий ( $\rho=1,000$, $\mathrm{p}=0,01)$. Однако, не было установлено подобной закономерности при анализе данных тестирования в Петровском колледже ( $\mathrm{p}=0,33$ и $\mathrm{p}=1,0$ соответственно) и СПб ГБПОУ "Академия транспортных технологий ( $\mathrm{p}=0,67$ и p=0,66 соответственно) (Табл.3).

Таблица 3. Динамические показатели тестирования методом ПЦР на SARS-CoV2 студентов и преподавателей колледжей г. Санкт-Петербурга в период с 25.01.22 по 27.01.22

\begin{tabular}{|c|c|c|c|c|c|c|c|c|}
\hline $\begin{array}{c}\text { Дата } \\
\text { отбора } \\
\text { матери } \\
\text { ала }\end{array}$ & $\begin{array}{c}\text { Район } \\
\text { расположе } \\
\text { ния } \\
\text { учреждени } \\
\text { я } \\
\end{array}$ & $\begin{array}{c}\text { Наименовани } \\
\text { е учебного } \\
\text { заведения }\end{array}$ & $\begin{array}{c}\text { Всего } \\
\text { обслед } \\
\text { овано, } \\
\text { n }\end{array}$ & $\begin{array}{c}\text { из них } \\
\text { положи } \\
\text { тельных } \\
\text {, n/\% }\end{array}$ & $\begin{array}{c}\text { из них } \\
\text { вариант } \\
\text { «Омикр } \\
\text { он», n/ } \\
\text { \% }\end{array}$ & $\begin{array}{c}\text { всего } \\
\text { обслед } \\
\text { овано }\end{array}$ & $\begin{array}{c}\text { из них } \\
\text { положите } \\
\text { льных, n/ } \\
\text { \% }\end{array}$ & $\begin{array}{c}\text { из них } \\
\text { вариант } \\
\text { «Омикр } \\
\text { он», n/ } \\
\text { \% }\end{array}$ \\
\hline \multirow{4}{*}{$\begin{array}{c}25.01 .2 \\
2\end{array}$} & Невский & $\begin{array}{l}\text { СПб ГБПОУ } \\
\text { "Академия } \\
\text { машинострое } \\
\text { ния им. } \\
\text { Ж.Я.Котина" }\end{array}$ & \multirow{4}{*}{1585} & \multirow{4}{*}{$\begin{array}{c}214 \\
/ 13 \%\end{array}$} & \multirow{4}{*}{$\begin{array}{l}109 \\
/ 51 \%\end{array}$} & 482 & 82 /17\% & $53 / 65 \%$ \\
\hline & $\begin{array}{c}\text { Кировски } \\
\text { й }\end{array}$ & $\begin{array}{l}\text { Петровский } \\
\text { колледж }\end{array}$ & & & & 399 & $45 / 11,3 \%$ & $19 / 42 \%$ \\
\hline & $\begin{array}{c}\text { Фрунзенс } \\
\text { кий }\end{array}$ & $\begin{array}{l}\text { СПб ГБПОУ } \\
\text { "Академия } \\
\text { транспортных } \\
\text { технологий" }\end{array}$ & & & & 345 & $34 / 9,8 \%$ & $13 / 38 \%$ \\
\hline & $\begin{array}{c}\text { Московск } \\
\text { ий }\end{array}$ & $\begin{array}{l}\text { Техникум } \\
\text { Отраслевых } \\
\text { Технологий }\end{array}$ & & & & 359 & $53 / 4,8 \%$ & $\begin{array}{c}24 \\
(45 \%)\end{array}$ \\
\hline \multirow{4}{*}{$\begin{array}{c}26.01 .2 \\
2\end{array}$} & Невский & $\begin{array}{l}\text { СПб ГБПОУ } \\
\text { "Академия } \\
\text { машинострое } \\
\text { ния им. } \\
\text { Ж.Я.Котина" } \\
\end{array}$ & \multirow{4}{*}{1694} & \multirow{4}{*}{$\begin{array}{c}255 \\
/ 15 \%\end{array}$} & \multirow{4}{*}{$\begin{array}{c}173 \\
/ 68 \%\end{array}$} & 424 & $74 / 17 \%$ & $47 / 64 \%$ \\
\hline & $\begin{array}{c}\text { Кировски } \\
\text { й }\end{array}$ & $\begin{array}{l}\text { Петровский } \\
\text { колледж }\end{array}$ & & & & 401 & $36 / 9 \%$ & $19 / 53 \%$ \\
\hline & $\begin{array}{c}\text { Фрунзенс } \\
\text { кий }\end{array}$ & $\begin{array}{l}\text { СПб ГБПОУ } \\
\text { "Академия } \\
\text { транспортных } \\
\text { технологий" }\end{array}$ & & & & 628 & $124 / 20 \%$ & $90 / 73 \%$ \\
\hline & Московск & Техникум & & & & 241 & $21 / 9 \%$ & $17 / 81 \%$ \\
\hline
\end{tabular}




\begin{tabular}{|c|c|c|c|c|c|c|c|c|}
\hline & ий & $\begin{array}{l}\text { Отраслевых } \\
\text { Технологий }\end{array}$ & & & & & & \\
\hline \multirow{4}{*}{$\begin{array}{c}27.01 .2 \\
2\end{array}$} & Невский & $\begin{array}{l}\text { СПб ГБПОУ } \\
\text { "Академия } \\
\text { машинострое } \\
\text { ния им. } \\
\text { Ж.Я.Котина" }\end{array}$ & \multirow{4}{*}{607} & \multirow{4}{*}{$71 / 12 \%$} & \multirow{4}{*}{38 /53\% } & 0 & 0 & 0 \\
\hline & $\begin{array}{c}\text { Кировски } \\
\text { й }\end{array}$ & $\begin{array}{l}\text { Петровский } \\
\text { колледж }\end{array}$ & & & & 345 & $40 / 12 \%$ & $13 / 32 \%$ \\
\hline & $\begin{array}{c}\text { Фрунзенс } \\
\text { кий }\end{array}$ & $\begin{array}{l}\text { СПб ГБПОУ } \\
\text { "Академия } \\
\text { транспортных } \\
\text { технологий" }\end{array}$ & & & & 254 & $27 / 11 \%$ & 22 /81\% \\
\hline & $\begin{array}{c}\text { Московск } \\
\text { ий }\end{array}$ & $\begin{array}{l}\text { Техникум } \\
\text { Отраслевых } \\
\text { Технологий }\end{array}$ & & & & 8 & 4 /50\% & 3 /75\% \\
\hline
\end{tabular}

Удельный вес инфицированных SARS-CoV2 в возрасте 14-17 лет варьировал в разных районах города от $11,5 \%$ до 47,6\%, составляя в среднем 20,6\%, из них вариант «Омикрон» выявлялся в 20,4-80,0\%, определяясь в среднем в 51,7\% положительных проб. В возрасте 18 лет и старше удельный вес положительных проб составлял 8,2-11,6\% в разных образовательных учреждениях, выявляясь в среднем 10,1\%. Вариант «Омикрон в этой возрастной категории варьировал от 24,2\% до 47,6\%, составляя в среднем 33,1\% (Табл.4).

Таблица 4

Зависимость выявления SARS-CoV2, включая вариант «Омикрон» методом ПЦР у лиц без клинических проявлений заболевания от возраста обследованных

\begin{tabular}{|c|c|c|c|c|c|c|}
\hline & \multicolumn{7}{|c|}{ Обследовано на SARS-CoV2 методом ПЦР студентов и преподавателей } \\
учебных заведений по возрастам
\end{tabular}




\begin{tabular}{|c|c|c|c|c|c|c|}
\hline $\begin{array}{c}\text { Петровский } \\
\text { колледж }\end{array}$ & 766 & $\begin{array}{c}11,5 / \\
88 \\
\end{array}$ & $\begin{array}{c}48,9 / \\
43 \\
\end{array}$ & 379 & $\begin{array}{c}8,7 / \\
33 \\
\end{array}$ & $\begin{array}{c}24,2 / \\
8 \\
\end{array}$ \\
\hline $\begin{array}{c}\text { СПб ГБПОУ } \\
\text { "Академия } \\
\text { транспортных } \\
\text { технологий" }\end{array}$ & 842 & $\begin{array}{c}16,6 / \\
140\end{array}$ & $\begin{array}{c}80,0 / \\
112\end{array}$ & 385 & $\begin{array}{c}11,6 / \\
45\end{array}$ & $\begin{array}{c}28,9 / \\
13\end{array}$ \\
\hline $\begin{array}{c}\text { Техникум } \\
\text { Отраслевых } \\
\text { Технологий }\end{array}$ & 390 & $\begin{array}{c}47,6 / \\
186\end{array}$ & $\begin{array}{c}20,4 / \\
38\end{array}$ & 218 & $\begin{array}{c}8,2 / \\
18\end{array}$ & $\begin{array}{c}33,3 / \\
6\end{array}$ \\
\hline $\begin{array}{c}\text { ИТОГО по } \\
\text { всем } \\
\text { учреждениям }\end{array}$ & 2603 & $\begin{array}{c}20,6 / \\
536\end{array}$ & $\begin{array}{c}51,7 / \\
277\end{array}$ & 1283 & $\begin{array}{c}10,1 / \\
130\end{array}$ & $\begin{array}{c}33,1 / \\
43\end{array}$ \\
\hline
\end{tabular}

Согласно полученным результатам (Табл.5), подростки в возрасте 14-17 лет статистически значимо чаще являлись бессимптомными носителями вируса, чем люди в возрасте 18 лет и старше (p<0,001). Шансы бессимптомного носительства коронавируса среди подростков 14-17 лет были в 2,3 раза выше. Кроме того, подростки 14-17 лет статистически значимо чаще были инфицировананы вариантом “Омикрон”, по сравнению с когортой исследуемых в возрасте 18 лет и старше $(\mathrm{p}<0,001)$. Шансы бессимптомного инфицирования вариантом “Омикрон” среди подростков 14-17 лет были выше в 3,3 раза, чем у взрослых.

Таблица 5. Анализ возрастной структуры обследованных в зависимости от результатов тестирования на SARS-CoV2.

\begin{tabular}{|c|c|c|c|c|}
\hline \multirow[b]{2}{*}{ Показатель } & \multicolumn{2}{|c|}{ Возрастная структура исследуемых } & \multirow[b]{2}{*}{$\mathrm{p}$} & \multirow[b]{2}{*}{ ОШ; 95 Ди\% } \\
\hline & 14-17 лет $(n=2603)$ & $\begin{array}{c}18 \text { лет и старше } \\
(\mathrm{n}=1283)\end{array}$ & & \\
\hline $\begin{array}{c}\text { ПЦР “+” на } \\
\text { SARS- } \\
\text { CoV2, n, } \\
\text { (\%) }\end{array}$ & $536(20,6)$ & $130(10,1)$ & $<0,001$ & $2,3(1,86-2,79)$ \\
\hline $\begin{array}{c}\text { вариант } \\
\text { «Омикрон» } \\
\text {, n, }(\%)\end{array}$ & $277(51,7)$ & $43(33,1)$ & $<0,001$ & $3,35(2,42-4,64)$ \\
\hline
\end{tabular}

При последующем наблюдении в течение 7 дней за позитивными по SARS-CoV2 лицами симптомы COVID-19 не развились. 
На увеличение бессимптомного носительства SARS-CoV2 после обнаружения варианта «Омикрон» ученые обратили внимание еще в начале декабря 2021 года при проведении клинических исследований в ЮАР и США по оценке эффективности вакцины mRNA-1273 (Moderna) среди ВИЧ-инфицированных. Из участников, пришедших на вакцинацию с 2 по 17 декабря 2021 года, 71 (31\%) оказались положительными по SARS-CoV2 при проведении ПЦР-тестирования. У всех этих участников исследования впоследствии был подтвержден вариант SARS-CoV2 «Омикрон». Частота бессимптомного носительства была одинаковой у серопозитивных и серонегативных лиц с SARS-CoV-2 (31\% и 27\%, соответственно). В предыдущий период исследования, до появления «Омикрона», частота выявления положительных результатов ПЦР перед первом проведением вакцинации составляла лишь <1\%-2,4\%. Это свидетельствует о том, что у Омикрона гораздо более высокая частота бессимптомного носительства, чем у других вариантов, и эта высокая распространенность бессимптомной инфекции, вероятно, является основным фактором широкого и быстрого распространения варианта во всем мире, даже среди населения с высокими показателями предшествующей инфекции SARS-COV-2 [15].

Высокая частота выявления бесимптомных и легких форм COVID-19, вызванного «Омикроном», среди пациентов, госпитализированных в связи с причинами, отличными от COVID-19, также сообщается исследователями из США. Удельный вес таких форм увеличился с 8,3\% в ноябре до 20,3\% в декабре 2021 [16]. По мнению ученых из Вьетнама около 90\% инфицированных вариантом «Омикрон» являются бессимптомными [17]. О большом удельном весе бессимптомных случаев инфекции, вызванной вариантом «Омикрон» (27,3\%) пишут и исследователи из Японии. Несмотря на достаточно низкие циклы ПЦР (Ct18-20) у обследованных, клинически инфекция не проявилась [18].

В нашем исследовании продемонстрирована высокая частота выявления бессимптомных позитивных по SARS-CoV2 лиц среди студентов и преподавателей образовательных учреждений г. Санкт-Петербурга в период подъема заболеваемости COVID19, вызванного преобладающим вариантом «Омикрон». В среднем, у подростков в возрасте 14-17 лет частота как положительных проб (20,6\%), так и удельный вес варианта «Омикрон» в позитивных пробах (51,7\%) были значимо выше, чем у лиц в возрасте 18 лет и старше ( $10,1 \%$ и 33,1\%, соответственно). Указанная закономерность прослеживалась во всех анализируемых образовательных учреждениях. Подростки в возрасте 14-17 лет статистически значимо, в 2,3 раза чаще, являлись бессимптомными носителями вируса, чем взрослые. Кроме того, подростки 14-17 лет значимо чаще (в 3,3 раза) были инфицированы вариантом “Омикрон”, по сравнению с когортой исследуемых лиц в возрасте 18 лет и старше. Отмечена 
значимая прямая корреляционная связь между увеличением числа тестируемых и вероятностью выявления бессимптомных носителей, в том числе, инфицированных вариантом «Омикрон»

Полученные результаты согласуются с малочисленными результатами исследований специалистов из других стран, посвященных оценке частоты бессимптомного носительства SARS-CoV2 в период подъема заболеваемости COVID-19, вызванного вариантом «Омикрон» [15-18].

Выводы: в период подъема заболеваемости COVID-19 в январе 2022 года отмечается высокая распространенность бессимптомного носительства вируса SARS-CoV2 среди студентов и преподавателей образовательных учреждений, расположенных в разных районах города. Подростки более чем в 2 раза чаще являются носителями SARS-CoV2 и более чем в 3 раза чаще носителями варианта «Омикрон», по сравнению со взрослыми. Это демонстрирует нецелесообразность обследования и изоляции контактных лиц, из числа учащихся и преподавателей образовательных учреждений, не имеющих клинических проявлений инфекции. Сохраняет актуальность обследование и изоляция лиц с симптомами заболевания, перевод лиц из групп риска на дистанционный режим работы или обучения. а также усиленный контроль за соблюдением мер неспецифической профилактики во всех общественных учреждениях.

Вклад авторов: Башкетова Н.С., Фридман Р.К. - дизайн исследования, организация набора материала, Катаева И.С., Шапарь А.О. - набор материала, лабораторные исследования, Костина М.С. - подготовка отдельных разделов публикации, Журавлев А.С. - статистическая обработка данных, Пшеничная Н.Ю. - описание результатов, подготовка результатов к публикации.

Конфликт интересов: авторы заявляют об отсутствии конфликта интересов.

\section{Список литературы}

\section{References}

1. Callaway E. Heavily mutated Omicron variant puts scientists on alert. Nature 2021; 600(7887): 21

2. Harvey WT, Carabelli AM, Jackson B, et al. SARS-CoV-2 variants, spike mutations and immune escape. Nat Rev Microbiol 2021; 19(7): 409-24;

3. D. Kim, J. Jo, J. S. lim, S. Ryu, Serial interval and basic reproduction number of SARSCoV-2 Omicron variant in South Korea. MedRxiv, 2021 https://doi.org/10.1101/2021.12.25.21268301 
4. Miller NL, Clark T, Raman R, Sasisekharan R. Insights on the mutational landscape of the SARS-CoV-2 Omicron variant. bioRxiv 2021.https://www.ncbi.nlm.nih.gov/pmc/articles/PMC8669838/

5. Lamers, M. M., Mykytyn, A. Z., Breugem, T. I., Groen, N., Knoops, K., Schipper, D., ... \& Haagmans, B. L. (2022). SARS-CoV-2 Omicron efficiently infects human airway, but not alveolar epithelium. bioRxiv. https://doi.org/10.1101/2022.01.19.476898

6. Jaffar A. Al-Tawfiq, Van-Thuan Hoang, Nhat Le Bui, Dinh-Toi Chu, Ziad A. Memish. Emergence of the Omicron (B.1.1.529) SARS-CoV-2 Variant: What is the Impact on the Continued Pandemic? Journal of Epidemiology and Global Health, 2022 [published online 28 January 2022, accessed 28.01.2022] https://doi.org/10.1007/s44197-022-00032-w

7. Xu, J., Li, Y., Gan, F., Du, Y., \& Yao, Y. (2020). Salivary glands: potential reservoirs for COVID-19 asymptomatic infection. Journal of dental research, 99(8), 989-989

8. Byambasuren, O., Cardona, M., Bell, K., Clark, J., McLaws, M. L., \& Glasziou, P. (2020). Estimating the extent of asymptomatic COVID-19 and its potential for community transmission: systematic review and meta-analysis. Official Journal of the Association of Medical Microbiology and Infectious Disease Canada, 5(4), 223-234;

9. Buitrago-Garcia, D., Egli-Gany, D., Counotte, M. J., Hossmann, S., Imeri, H., Ipekci, A. M., ... \& Low, N. (2020). Occurrence and transmission potential of asymptomatic and presymptomatic SARS-CoV-2 infections: A living systematic review and meta-analysis. PLoS medicine, 17(9), e1003346

10. Meyerowitz EA, Richterman A, Bogoch II, Low N, Cevik M. Towards an accurate and systematic characterisation of persistently asymptomatic infection with SARS-CoV-2. Lancet Infect Dis2020;S1473-3099(20)30837-9.pmid:33301725

11. He, J., Guo, Y., Mao, R., \& Zhang, J. Proportion of asymptomatic coronavirus disease 2019: A systematic review and meta-analysis. Journal of medical virology, 2021 93(2), 820-830;

12. Yanes-Lane, M., Winters, N., Fregonese, F., Bastos, M., Perlman-Arrow, S., Campbell, J. R., \& Menzies, D. (2020). Proportion of asymptomatic infection among COVID-19 positive persons and their transmission potential: A systematic review and meta-analysis. 2021 PloS one, 15(11), $\mathrm{e} 0241536$

13.He, J., Guo, Y., Mao, R., \& Zhang, J. Proportion of asymptomatic coronavirus disease 2019: A systematic review and meta-analysis. Journal of medical virology, 2021 93(2), 820-830;

14. Yanes-Lane, M., Winters, N., Fregonese, F., Bastos, M., Perlman-Arrow, S., Campbell, J. R., \& Menzies, D. (2020). Proportion of asymptomatic infection among COVID-19 positive persons and their transmission potential: A systematic review and meta-analysis. 2021 PloS one, 15(11), $\mathrm{e} 0241536$

15. Garret, N., Tapley, A., Andriesen, J., Seocharan, I., Fisher, L. H., Bunts, L., ... \& Corey, L. High rate of asymptomatic carriage associated with variant strain Omicron. MedRxiv. 2021, Posted January 14, 2022. https://doi.org/10.1101/2021.12.20.21268130

16. Klompas, M., \& Karan, A. Preventing SARS-CoV-2 Transmission in Health Care Settings in the Context of the Omicron Variant. JAMA. Published online January 24, 2022. doi:10.1001/jama.2022.0262

17. Bao CC, Bihn D. Spread of Local Transmission Virus That Causes Health Problems From Public Transportation . JAMRMHSS [Internet]. 2022Jan.24 [cited 2022Jan.30];3(1):18-22. Available from: https://www.amrsjournals.com/index.php/jamrmhss/article/view/233

18. Okumura, N., Tsuzuki, S., Saito, S., Saito, T., Takasago, S., Hojo, M., ... \& Ohmagari, N. (2021). The first eleven cases of SARS-CoV-2 Omicron variant infection in Japan: A focus on viral dynamics. Global Health \& Medicine https://doi.org/10.35772/ghm.2021.01124 


\section{Сведения об авторах}

\section{Information about authors}

Башкетова Наталия Семеновна. Руководитель Управления Федеральной службы по надзору в сфере защиты прав потребителей и благополучия человека по городу СанктПетербургу. Адрес: 191025, г. Санкт-Петербург, ул. Стремянная, д. 19, тел. +7 (812)764-42-38, e-mail uprav@78rospotrebnadzor.ru;

Bashketova Natalia Semenovna. Head of the Department of the Federal Service for Supervision of Consumer Rights Protection and Human Welfare in the city of St. Petersburg. Address: 19 Stremyannaya str., St. Petersburg, 191025, tel. +7 (812)764-42-38, email address uprav@78rospotrebnadzor.ru;

Фридман Роман Кириллович, кандидат медицинских наук, Главный врач ФБУЗ «Центр гигиены и эпидемиологии в городе Санкт-Петербург», 192102, Санкт-Петербург, Волковский пр., 77, тел. +7 (812) 571-37-31, E-mail: centr@78cge.ru;

Fridman Roman Kirillovich, Candidate of Medical Sciences, Chief Physician of the Federal Medical Institution "Center of Hygiene and Epidemiology in the City of St. Petersburg", 192102, St. Petersburg, Volkovsky Ave., 77, tel. +7 (812) 571-37-31, E-mail: centr@78cge.ru;

Катаева Ирина Сергеевна, заместитель начальника отдела эпидемиологического надзора Управления Федеральной службы по надзору в сфере защиты прав потребителей и благополучия человека по городу Санкт-Петербургу. Адрес: 191025, г. Санкт-Петербург, ул. Стремянная, д. тел. +7 (812)764-42-38, e-mail yvarova-irina@yandex.ru;

Kataeva Irina Sergeevna, Deputy Head of the Department of Epidemiological Surveillance of the Federal Service for Supervision of Consumer Rights Protection and Human Welfare in the city of St. Petersburg. Address: 191025, St. Petersburg, Stremyannaya str., tel. +7 (812)764-42-38, email yvarova-irina@yandex.ru;

Шапарь Александр Олегович. Заведующий отделом эпидемиологии, паразитологии и дезинфектологии с группой учета и регистрации инфекционных и паразитарных заболеваний ФБУЗ «Центр гигиены и эпидемиологии в городе Санкт-Петербург», 192102, Санкт-Петербург, Волковский пр., 77, тел. +7 (812) 570-60-76, E-mail: centr@78cge.ru;

Shapar Alexander Olegovich. Head of the Department of Epidemiology, Parasitology and Disinfection with the group of accounting and registration of infectious and Parasitic Diseases of the Center for Hygiene and Epidemiology in St. Petersburg, 192102, St. Petersburg, Volkovsky Ave., 77, tel. +7 (812) 570-60-76, E-mail: centr@78cge.ru

Костина Марина Алексеевна. Начальник Управления контрольно-надзорной деятельности и организации санитарно-эпидемиологического нормирования Роспотребнадзора, 127994, Москва Вадковский переулок дом 18, строение 5 и 7, тел. 8 (499) 973-26-90, e-mail: e-mail: depart@gsen.ru

Костина Марина Алексеевна. Начальник контрольно-надзорной деятельности Управления и организации санитарно-эпидемиологического нормирования Роспотребнадзора, 
127994, Москва Вадковский переулок дом 18, строение 5 и 7, тел. 8 (499) 973-26-90, электронная почта: e-mail: depart@gsen.ru

Kostina Marina Alekseevna. Head of Control and Supervisory Activities of the Department and Organization of Sanitary and Epidemiological Rationing of Rospotrebnadzor, 127994, Moscow Vadkovsky lane house 18, building 5 and 7, tel. 8 (499) 973-26-90, e-mail: e-mail: depart@gsen.ru

Журавлев Андрей Сергеевич. Младший научный сотрудник отделения рентгенэндоваскулярной хирургии ГБУЗ МО «МОНИКИ им.М.Ф.Владимирского», 129110 г. Москва, ул.Щепкина, 61/2, тел +7 (495) 681-03-03, E-mail: and0898@yandex.ru;

Zhuravlev Andrey Sergeevich. Junior Researcher of the Department of X-ray endo-vascular Surgery of the State Medical Institution "MONIKI named after M.F.Vladimirsky", 61/2 Shchepkina str., Moscow, 129110, tel +7 (495) 681-03-03, E-mail: and0898@yandex.ru

Пшеничная Наталья Юрьевна, доктор медицинских наук, профессор. Заместитель директора по клинико-аналитической работе ФБУН «Центральный научно-исследовательский институт эпидемиологии» Роспотребнадзора, 111124, Москва, Новогиреевская, За, тел +7 (495) 974-96-46, доб.1205, E-mail: pshenichnaya@cmd.su;

Pshenichnaya Natalia Yurievna, Doctor of Medical Sciences, Professor. Deputy Director for Clinical and Analytical Work of the Central Research Institute of Epidemiology of Rospotrebnadzor, Novogireevskaya 3a, Moscow, 111124, tel +7 (495) 974-96-46, ext.1205, E-mail: pshenichnaya@cmd.su 